\title{
Synthesis and Mechanical Behavior of Composite Material Reinforced with Guadua Fiber and with a Polyurethane or Polyester Matrix
}

\author{
Ricardo Acosta, ${ }^{\mathrm{a}, *}$ Gabriel Calle Trujillo, ${ }^{\mathrm{b}}$ and José Luddey Marulanda Arévalo ${ }^{\mathrm{c}}$ \\ A reactive hot-melt resin (polyurethane) was used to manufacture Guadua \\ composites with a certain flexibility, high processing speed, good initial \\ rigidity, and high temperature performance. These composites can \\ support a moderate tensile stress, allow for large strains at low stresses, \\ and have a low density and a working temperature range of $-40^{\circ} \mathrm{C}$ and \\ $110{ }^{\circ} \mathrm{C}$. During the flexural test, bamboo composites with reactive \\ polyurethane matrix do not break or fail during the test. A polyurethane- \\ based reactive hot-melt resin was characterized by tensile tests, Shore \\ hardness tests, differential scanning calorimetry, and thermogravimetry. \\ Besides, a composite material was made with Guadua fiber and polyester \\ matrix, which had a greater strength in the test of tension and flexion, \\ although it had a lower percentage of elongation than the composite \\ material with reactive polyurethane. Guadua fiber can increase the \\ strength by $266 \%$ of polyurethane matrix and $228 \%$ of polyester matrix.
}

Keywords: Hot melt adhesive; Characterization; Composite material; Guadua fiber

Contact information: a: School of Technology, Technological University of Pereira, Pereira, Colombia; b: Mechanical Engineering Faculty, Technological University of Pereira, Pereira, Colombia; c: Mechanical Engineering Faculty, Technological University of Pereira, Pereira, Colombia;

*Corresponding author: ricosta@utp.edu.co

\section{INTRODUCTION}

Polymer composite material (PMC) consists of thermoplastic or thermosetting polymer as a matrix with one or more reinforcements, such as carbon, Kevlar, glass, steel, or natural fibers. These composites are used in various industrial applications due to their high specific strength and stiffness, light weight, corrosion resistance, reparability, fatigue resistance, and low cost. PMC can produce good components, as they can be processed conveniently. The mechanical and chemical characteristics of the fibers, matrix, and interface influence in the mechanical properties, besides the way in which the composite deforms and fractures (Andrew et al. 2019: Aruchamy et al. 2020). The most advanced polymer-matrix structural composites are those that involve continuous fibers, such as carbon fibers, which are attractive for their combination of low density, high strength, and high modulus of elasticity (Marulanda et al. 2020). Glass, Kevlar, and carbon fiber reinforced composites do have excellent mechanical properties but are non-renewable, non-ecofriendly, and can cause human health issues. The natural fiber reinforced composites were developed because of their ability to reduce or replace synthetic fibers in many engineering applications (Sharma et al. 2020; Lu et al. 2020).

The development of biocomposite materials has attracted considerable interest due to environmental problems and depletion of fossil resources. The combination of natural fiber with polymer matrices (both renewable and non-renewable resources) is called a

Acosta et al. (2021). "Guada fiber PU PE composites," BioResources 16(4), 8049-8059. 8049 
biocomposite. These composites are very important due to their abundance, light weight, contribution towards reduction of harmful solid-waste deposition and green-house gases emission; in addition, these materials can be recycled and used for different purpose with enhanced properties and even at low price (Tokala and Mulpur 2019; Sormunen and Kärki 2019). Natural fiber-reinforced polymer composite has a huge affinity to interchange the composite made up of synthetic fiber. The mechanical behavior of this biocomposites is influenced by several parameters such as fiber volume fraction, fiber length, fiber-matrix adhesion, fiber orientation, and stress transfer at the interface. Therefore, to improve the mechanical behavior of composite materials, the properties of matrix and fibers must be improved first (Vaghasia and Rachchh 2018; Andrew et al. 2019; Kalali et al. 2019; Sair et al. 2019; Sormunen and Kärki 2019; Tokala and Mulpur 2019; Aruchamy et al. 2020; Lokesh et al. 2020; Lu et al. 2020; Sharma et al. 2020) Several composites are utilized nowadays that were developed via innovation together with efficiency at the optimum price. The natural fiber composites have begun to be used in secondary structural applications in the automotive industry, including door panels and package trays, because of their low material and production costs, acceptable mechanical properties, biodegradability, and lower weights (Barari et al. 2016).

Guadua is a woody bamboo that belongs to the grass family. Colombia has one of the species that has the best physical-mechanical properties in the world and extraordinary durability: Guadua angustifolia. Among commonly used bio-based resources, Guadua is a very attractive source for manufacturing high-performance composite materials. Besides, mechanical properties of Guadua fibers are comparable to those of glass fibers or hard woods, but Guadua fiber are more cost effective than hard woods, due to the much shorter growth cycle. Therefore, Guadua fibers are considered promising candidates for the reinforcement of composite materials due to its low-density, high stiffness and high strength, which makes them abundantly available (Lokesh et al. 2020; Chin et al. 2020). Bamboo grows as a system of roots (technically, rhizomes) that produce culms. Their fast rate of growth can reach full height (up to $20 \mathrm{~m}$ ) in as little as 3 months. For some species, this is a rate of growth of $1 \mathrm{~m}$ a day (Kuehl and Yiping 2012). However, culms will require a period of maturation before they have optimal strength for structural applications. This period ranges from 3 to 6 years. In a similar manner to other materials, in particular timber, the strength of bamboo correlates well with its density. Density values correlate well with compressive, bending, and tensile strength; this is likely to be because denser samples have a higher content of cellulose (Trujillo and Lopez 2016; Gou et al. 2019).

The Guadua fiber cannot be obtained directly from the Guadua culm, and several treatments are needed before the fiber can be obtained. The Guadua fiber preparation methods include retting, steam, alkali treatment, degumming, grinding, and crushing. The quality and strength of the fibers is directly affected by the extraction method used. Thermoplastic composites reinforced with chemically treated Guadua fiber offer better mechanical and physical properties. For this reason, Guadua was treated with $2 \% \mathrm{NaOH}$ by weight (Lokesh et al. 2020). The alkali treatment modifies the fiber surface, which helps to remove the lignin and wax from outer surface resulting in better adhesion between fiber and polymeric matrix (Vaghasia and Rachchh 2018; Chin et al. 2020).

The present study focused on the use of Guadua fiber and hot melt polyurethane (PUR) as a composite material matrix. The performance of this type of matrix depends on its rapid crystallization during cooling, which favors quick solidification and welding. The interface compatibility between the Guadua fiber and the matrix is an important issue in the development of this composite materials since their mechanical properties depend on

Acosta et al. (2021). "Guada fiber PU PE composites," BioResources 16(4), 8049-8059. 8050 
the interactions between the reinforcement and the polymer chains. The resin behavior differs with a change of atmosphere because the environmental humidity affects the resincrosslinking reactions. The glass transition temperature $\left(T_{\mathrm{g}}\right)$ depends on the heating and cooling rates used in the DSC run, molecular weight, plasticizer content, sample size, crosslinking, crystallinity, and degree of cure. The hot-melt resin contains ethylene-co-vinyl acetate with wax. The wax is included because its addition increases the crystallization kinetics of the system, which was observed between 50 and $65^{\circ} \mathrm{C}$. The wax is usually seen as a component that can reduce the cost and control the viscosity during processing. To a large extent, the final properties of matrix depend on the degree of crystallization achieved by hot melt polyurethane (Canales et al. 2016; Borgaonkar et al. 2018; Marulanda et al. 2019). The aligned microstructure of Guadua fibers is expected to improve the mechanical properties of unidirectional polymer composite materials. The structural and morphological features of the composite materials were investigated by optical microscopy; thermal properties were characterized by thermogravimetric analysis (TGA) and mechanical properties were evaluated by tensile and flexural tests.

\section{EXPERIMENTAL}

Guadua was harvested between three and four years, and the central area of the Guadua was taken. The Guadua culms without nodes were cut from $300 \mathrm{~mm}$ x $20 \mathrm{~mm}$ x $10 \mathrm{~mm}$ and washed with distilled water for $10 \mathrm{~min}$, then chemically treated with $2 \% \mathrm{wt} / \mathrm{v}$ sodium hydroxide $(\mathrm{NaOH})$ for $4 \mathrm{~h}$ at room temperature. After reaching the required immersed duration, the Guadua were mechanically defibrated using a mill roller machine to obtain the fiber, the chemical and mechanical treatment was repeated four times.

The Guadua fibers were washed with distilled water to remove impurities, and a neutral $\mathrm{pH}$ was obtained; it was finished with drying at $103{ }^{\circ} \mathrm{C}$ for $24 \mathrm{~h}$. Figure 1 shows the Guadua fibers and the test pieces for the tension test. Figure 1a shows Guadua fibers, which had lengths around $250 \mathrm{~mm}$. In Fig. 1b, the specimens of composite material of Guadua and polyurethane as matrix have many visible pores, while the specimens of composite material with polyester resin have very little porosity. All the Guadua fibers were not aligned during the manufacturing process since some fibers were misaligned during hand-laying. The manufacturing process of the composite material with a polyurethane matrix is governed by pressure, temperature, and process time. When more time and / or temperature than required is added, the matrix can generate porosity due to the acceleration of curing. In addition, the pressure allows the entry of the polymer into the fiber arrangement and the reduction of pores. Therefore, it is necessary to improve the melting times and the manufacturing pressure of this composite material. The samples were made with percentages of 6,8 , and $10 \%$ of Guadua fibers, where the best results were obtained with $10 \%$ of fiber.

Thermogravimetric differential scanning calorimetry (DSC) and thermogravimetry (TGA) analyses was carried out on an SDT Q600 thermobalance, which allows the simultaneous measurement of DSC and TGA. The thermograms were obtained between 21 ${ }^{\circ} \mathrm{C}$ and $200{ }^{\circ} \mathrm{C}$ at a heating rate of $5{ }^{\circ} \mathrm{C} / \mathrm{min}$ in both air atmosphere. Approximately 7 to 8 mg of each adhesive sample was placed inside an alumina crucible for DSC-TGA thermal analysis.

Acosta et al. (2021). “Guada fiber PU PE composites," BioResources 16(4), 8049-8059. 8051 

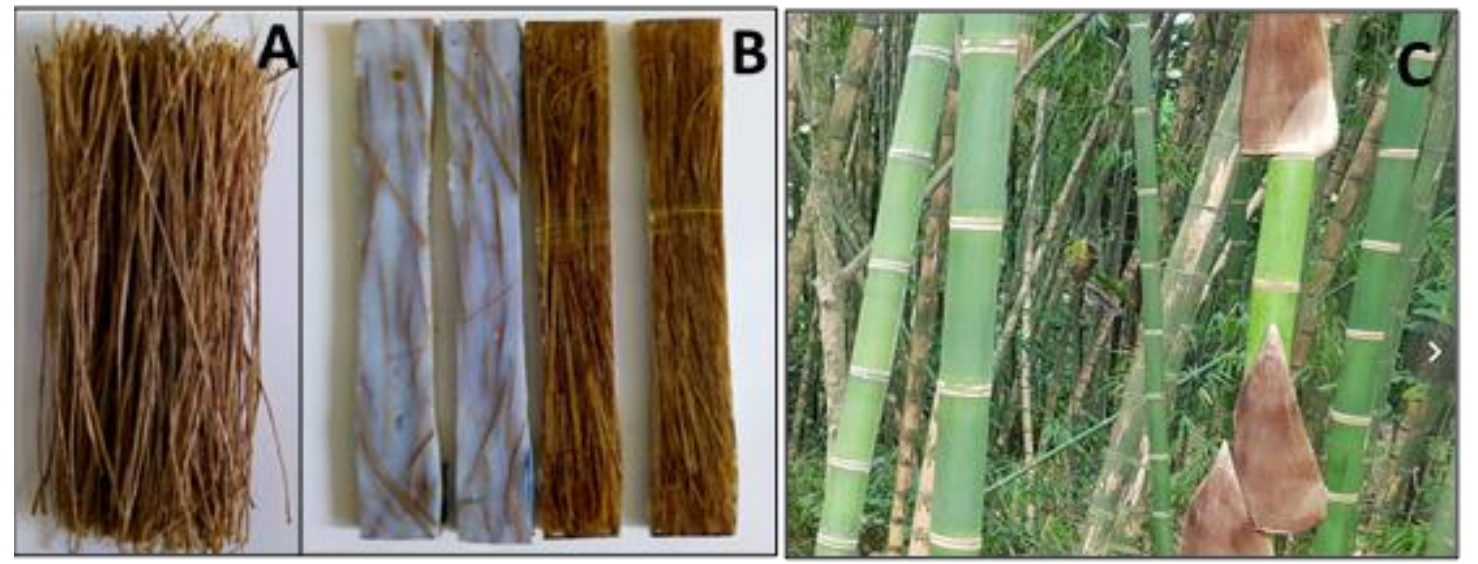

Fig. 1. Guadua fibers, specimens to tensile test and Guadua plant

For the matrix, 330-mL Jowatherm-Reaktant 642.00 cartridges were used. These cartridges are polyurethane-based reactive hot melt. Because its application properties are a function of temperature, it is necessary to heat and maintain the matrix at a constant temperature to guarantee its viscous liquid state. The growth of hardness hot melt reactive remains high until approximately $48 \mathrm{~h}$ of cure, after which the rate of hardening decreases and begins to be much slower. From $188 \mathrm{~h}$, the hardness is stabilized, which was apparent from the observation that at $336 \mathrm{~h}$ of curing, the Shore-A hardness was 92 . The bond strength increases gradually with time and depends on moisture. In addition, for this type of resin (reactive hot melt) the curing time is an important factor that influences its mechanical properties. The resin hardness did not change when fibers were added (Marulanda et al. 2019). To manufacture the composite material test specimens, the matrix was melted at 130 to $140{ }^{\circ} \mathrm{C}$ in a muffle furnace with a sensitivity of $+/-3{ }^{\circ} \mathrm{C}$ and dimensions of $40 \mathrm{~cm} \times 30 \mathrm{~cm} \times 30 \mathrm{~cm}$. Once the matrix had melted, it was emptied into a Teflon mold at $130{ }^{\circ} \mathrm{C}$, ensuring that the matrix was evenly distributed throughout the mold. The reinforcement (Guadua fiber) was introduced into the mold with continued supply of the matrix, once more ensuring that it was evenly distributed. Finally, the mold was closed, and pressure was applied to reduce the porosity and improve the uniformity of the composite material. A sample containing only hot melt polyurethane matrix was also produced and used as the control for comparison. To manufacture the polyester composite material test specimens, the polyester resin was placed in a $200 \mathrm{~mL}$ glass beaker and weighed on an electronic balance. Next, catalyst was added with a disposable syringe at the ratio of $100 \mathrm{~mL}$ of polyester resin 856 to $1 \mathrm{~mL}$ of catalyst (methyl ethyl ketone peroxide-MEKP) and stirred for about two minutes. A thin layer of catalyzed polyester resin was poured into the Teflon mold coated with petroleum jelly as mould release agent. Fiber reinforcement was placed by hand in a mold, and fiber was pressed against the mold with a roller to remove porosity. Then another layer of catalyzed polyester resin was placed into the mold. Finally, the mold was closed, and pressure was applied to reduce the porosity and improve the uniformity of the composite material. The test samples were cured for 24 $\mathrm{h}$, after which they were removed from the molds. Sample containing only a polyester matrix was also produced and used as the control for comparison. After making the composite material, six specimens were cut $(250 \mathrm{~mm} \times 25 \mathrm{~mm} \times 2.5 \mathrm{~mm})$ according to stress-test measurements from ASTM D 3039 (2017). Six specimens were cut for each material $(110 \mathrm{~mm} \times 13 \mathrm{~mm} \times 3.5 \mathrm{~mm})$ according to flexural tests using standard ASTM D 7264 (2015). The tensile and flexure tests were carried out using a universal testing

Acosta et al. (2021). "Guada fiber PU PE composites," BioResources 16(4), 8049-8059. 8052 
machine single-column force tester with capacities of 1,500 lbF (6.7 kN) (MARK-10 ESM1500, Mark-10 Corporation, NY, USA) a constant crosshead speed of $1 \mathrm{~mm} / \mathrm{min}$ at room temperature $\left(23^{\circ} \mathrm{C}\right)$.

\section{RESULTS AND DISCUSSION}

DSC-TGA was performed to observe the matrix behavior in air atmosphere as a function of temperature before and after making the composite material, as can be seen in Fig. 2. The resin behavior differs because the curing time affects the resin-crosslinking reactions. In Fig. $2 \mathrm{~A}$ it is apparent that the variation of heat capacity led to a small softening of the hot-melt polyurethane at $\sim 38{ }^{\circ} \mathrm{C}$, because the polyolefins in the resin are remarkably flexible. The glass-transition temperature $\left(T_{\mathrm{g}}\right)$ of the polyurethane resin before curing time was observed at $\sim 55^{\circ} \mathrm{C}$. This behavior is not observed in Fig. $2 \mathrm{~B}$. After curing, the polyurethane only exhibited a small melting of wax and polyolefins, as shown in Fig. $2 \mathrm{~B}$. The addition of waxes and polyolefins influenced the glass-transition temperature. The $T_{\mathrm{g}}$ depends on the heating and cooling rates used in the DSC run, molecular weight, plasticizer content, sample size, cross-linking, crystallinity, and degree of cure. Figure $2 \mathrm{~A}$ shows that the melting of most resin compounds occurred after $\sim 75^{\circ} \mathrm{C}$. The adhesive at $75^{\circ} \mathrm{C}$ is not liquid but exists in a gummy state; the Fig. 2B only shows a little fusion of compounds such as waxes and polyolefins. The resin mass gain is different before and after curing. In Fig. 2A, the slope of the mass gain by volatilization and reaction begins at $75^{\circ} \mathrm{C}$ to $95^{\circ} \mathrm{C}$, then tries to stabilize to $130{ }^{\circ} \mathrm{C}$, continues with a slope change at $135{ }^{\circ} \mathrm{C}$ due to the fluidization of the polyurethane, and $170{ }^{\circ} \mathrm{C}$ has a slope change because of the resin degradation. In Fig. 2B, the polyurethane resin has a mass gain and a little mass change at $75^{\circ} \mathrm{C}$, due to melting of some resin compounds.

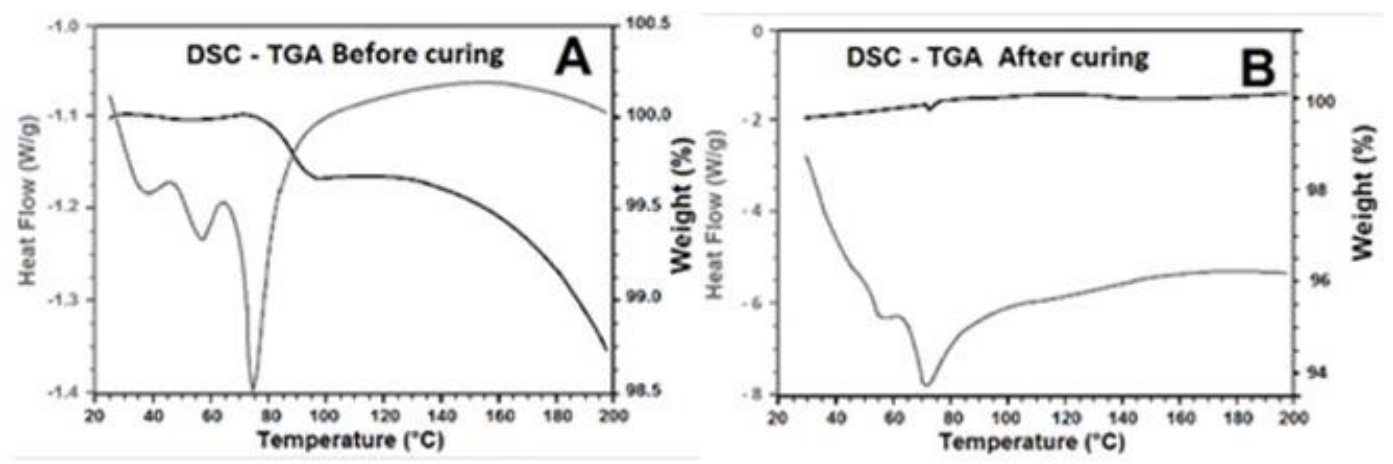

Fig. 2. DSC and TGA analysis for polyurethane resin in air atmospheres before and after of matrix cure

The polyester resin composite material is fragile with respect to the JowathermReaktant hot melt, which is elastic in nature, but when solidified and after $92 \mathrm{~h}$ of curing it becomes a more rigid material. During the stress test, the composite material with polyurethane matrix had an elongation of the matrix before the fibers fracture, contrary to what happens with the fibers in the polyester resin compound where the matrix and the fibers fail at the same time.

The tensile strength of composite materials depends on the properties of their constituents, such as bonding between fiber and matrix, the volumetric fraction, fiber 
length, fiber content, and the spatial distribution of the fibers; both the tenacity of the fibers and the interaction between the fibers and the matrix are crucial to the mechanisms involved in breaking stress and energy dissipation (Fernandez et al. 2017; Borgaonkar et al. 2018).

In Fig. 3, linear/elastic behaviors were observed between the deformation and the stress applied to the reactive polyurethane matrix specimen without reinforcement. This matrix reached deformations of $600 \%$, with applied pressure of $18.5 \mathrm{MPa}$; the initial measurements of the samples $\left(L_{\mathrm{o}}\right)$ were $80 \mathrm{~mm}$ and the final measurements before the stress test break $\left(L_{\mathrm{f}}\right)$ were around $486 \mathrm{~mm}$. Observing the area under the stress-strain curve; it can be stated that the material had a great toughness, and its data showed a low dispersion (5\%). During the tensile test, a long neck phenomenon was observed in the reactive polyurethane specimen. The neck-forming area was propagated along the direction of the tensile test until almost the entire sample had been homogeneously deformed. In some tests, failure was not achieved and after unloading the specimens could not regain their initial shape and maintain a permanent deformation of $150 \%$. Due to the capacity of the tensile test machine, it reached the maximum displacement, and the specimen did not break. The authors continued to reduce the length of the specimens. In this test, no softening of the polyurethane was observed, since during the beginning of the test it showed a linear elastic region and continued with a progressive hardening of the polyurethane until rupture (Fig. 3 ). This material exhibited viscoelastic behavior in the stress-strain test because it exhibited both viscous and elastic characteristics. The viscoelastic behavior was observed when the deformation of materials caused by stress was applied, linearly with time due to stress.

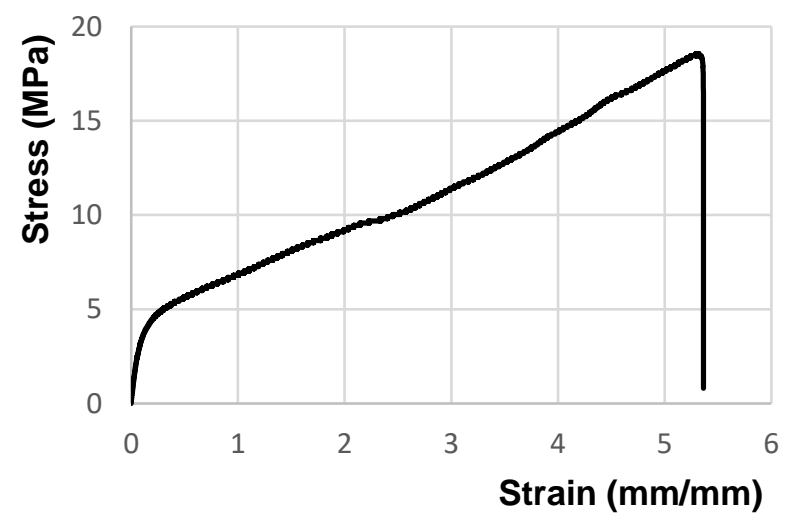

Fig. 3. Results of tensile tests on polyurethane matrix composites

Figure 4 shows the composite material with Guadua reinforcement and reactive polyurethane matrix. This material did not have a linear behavior between the matrix and the reinforcement, since at the beginning of the test there were large deformations with small applications of stress. This behavior can be attributed to the arrangement of the matrix and the reinforcement, after which a linear / elastic behavior was observed between the deformation and the stress, leading to an increase with a different slope in the displacement. The composite material of Guadua and polyurethane matrix withstood almost $48 \mathrm{MPa}$ (maximum strength), and its elongation displacement was $11.84 \mathrm{~mm}$. This material was more ductile than the composite material with a polyester matrix, since it allowed greater deformation before failing, although it had a high porosity, and it was necessary to continue working to reduce it and improve its mechanical resistance. The

Acosta et al. (2021). "Guada fiber PU PE composites," BioResources 16(4), 8049-8059. 8054 
composite material with polyurethane matrix had type-LGM failure mode, according to ASTM D3039 (2017), with high elastic material deformation, but with few yield points before the fracture mechanism.

Figure 4 shows the composite material with Guadua reinforcement and a polyester matrix. This material had a higher tensile strength supporting $79.7 \mathrm{MPa}$ (maximum strength) and its elastic limit was 64.1 MPa and elastic modulus was measured between 20 and $80 \%$ of the elastic limit. The maximum elongation displacement was $7.18 \mathrm{~mm}$. This composite material was more fragile and presented greater homogeneity and compaction of the matrix and the Guadua fiber reinforcement since the porosity was very low. Guadua fiber reinforcements were the elements that improved load transfer, offering the structure greater strength and rigidity. Figure $4 \mathrm{~b}$ shows the brittle nature that resulted in the catastrophic failure of the material composite, because no yield points existed before the fracture mechanism. The composite material with polyester matrix had type-AGM(2) failure mode, according to ASTM D3039 (2017), which is characterized by a fragile behavior during fracture with low elastic material deformation. The polyester matrix could resist more than $45 \mathrm{MPa}$, and the composite material with Guadua resists almost $80 \mathrm{MPa}$, increasing a maximum of $177 \%$ the capacity to support the load. The average results for each of the results are detailed in Table 1.

Table 1. Tension and Flexion Tests MOR Results

\begin{tabular}{|c|l|c|c|c|c|}
\hline Test type & Material & Samples & $\begin{array}{l}\text { MOR } \\
(\mathrm{MPa})\end{array}$ & COV (\%) & $\begin{array}{l}\text { Peak MOR } \\
\text { (MPA) }\end{array}$ \\
\hline \multirow{2}{*}{ Tensile test } & polyurethane & 4 & 34.3 & 25.5 & 47.3 \\
\cline { 2 - 6 } & polyester & 5 & 71.26 & 8.8 & 79.7 \\
\hline \multirow{2}{*}{ Flexural test } & Guadua polyurethane & 4 & 22.7 & 26.4 & 31.8 \\
\cline { 2 - 6 } & Guadua polyester & 7 & 83.9 & 14.9 & 98.7 \\
\hline
\end{tabular}

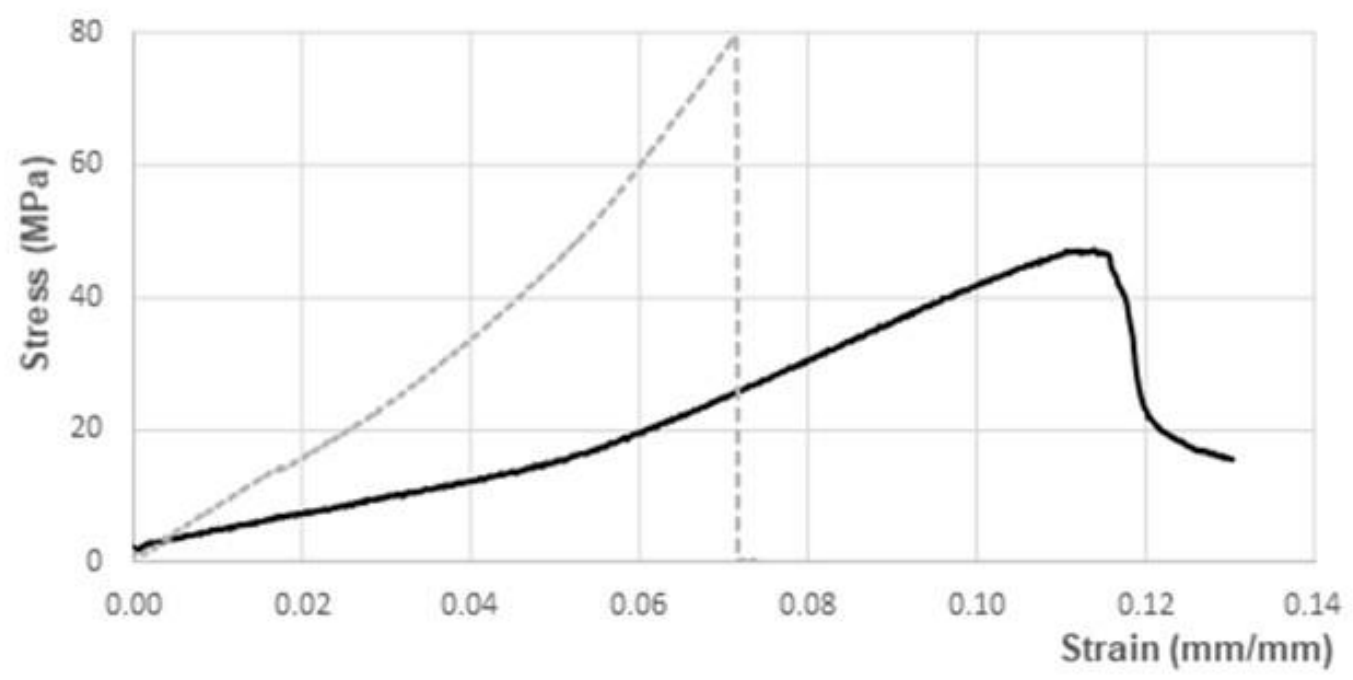

Polyester matrix Polyurethane matrix

Fig. 4. Results of tensile tests on composites reinforced with Guadua 
The polyurethane matrix was able to resist $18 \mathrm{MPa}$, and the composite material with Guadua resisted almost $48 \mathrm{MPa}$, increasing the strength by $266 \%$. The area under the curve in the stress / deformation diagram of the composite material with Guadua fiber with polyurethane was larger than the composite material of Guadua with polyester; therefore, it could be said that the composite material with polyurethane will have better impact strength, since composite materials with larger areas under the stress/strain curve are more efficient in absorbing energy. This is a quick and practical way to have a guide to the impact strength of composite materials.

Other studies of natural fibers report different behaviors of natural fibers. Aruchamy et al. (2020) reported: The tensile strength of woven cotton composite materials and epoxy matrix reached a maximum of $72.9 \mathrm{MPa}$ at $45 \%$ by weight of cotton, so that the strength did not increase after increasing the fiber content more beyond the critical fiber load content. In addition, the composite materials were prepared with mixtures of cotton fibers and bamboo fibers, obtaining a maximum tensile stress of $82.1 \mathrm{MPa}$ with $45 \%$ by weight of the fiber mixture (Andrew et al. 2019). Venkata Naga and Sarat Babu reported that composite materials with sugarcane fibers, coconut fibers and the hybrid composite based on cashew shell resin exhibited a tensile strength of 11.5, 2.6, and 5.9 $\mathrm{MPa}$, respectively (Tokala et al. 2019). Bhavik Vaghasia and Nikunj Rachchh reported that composite materials with mixtures of fiberglass $19 \%$ by weight and bamboo fiber from 3 to $15 \%$ by weight reached a maximum stress of $108 \mathrm{MPa}$ when they had $9 \%$ bamboo fiber (Vagashia et al. 2018). Lokesh et al. (2020) made a composite material with epoxy-epoxy resin and short bamboo fiber, which reached tensile stresses between 6.74 and 18.07 MPa.

The amount of fiber content that could be added without difficulty in the composite material manufacturing process was $12 \%$ by weight. For higher fiber contents it is difficult to maintain the size and thickness of the plates to make the specimens for the bending and tension test. In addition, the content of air bubbles between the bamboo fiber and the matrix is increased. This leads to discontinuity and reduces the homogeneity of the material, which results in a reduction of the tensile strength with a higher fiber content. This may be due to a lesser amount of resin available to impregnate the fibers, leading to less charge transfer between the fiber and the matrix (Vaghasia et al. 2018; Lokesh et al. 2020).

Flexural tests were conducted to determine the mechanical properties of the Guadua fiber composite and matrix. Figure 5 shows graphs of flexural tests by procedure A for composite materials of Guadua fiber with polyester matrix and Guadua fiber with reactive polyurethane matrix. The test load was applied at the midpoint of three support points. All the Guadua fiber and polyester matrix specimens showed fractures in the middle during the flexural test. Guadua composite materials with reactive polyurethane matrix did not break or fail during testing, showing good adhesion between matrix and fiber reinforcements, as bending tests can be used to get a qualitative idea of the strength of the fiber/composite matrix interface. Polyurethane matrix composites underwent deformation during the test, but they returned to their initial state and position after some time of removing the test load. Furthermore, these reactive adhesive composites did not present linear curves, which confirms the ductile behavior at low stresses of the material.

The maximum flexural stress of these materials was $80 \mathrm{MPa}$ for the composite material of Guadua fiber and epoxy matrix, $48 \mathrm{MPa}$ for the composite material with polyurethane matrix, and $36 \mathrm{MPa}$ for the reactive adhesive matrix. This makes it possible for composite materials with reactive polyurethane to be employed to manufacture different parts such as suspension springs and bumpers, among others. The benefits offered by hot melt polyurethane over conventional hot melts lie in the cross-linked structure,

Acosta et al. (2021). "Guada fiber PU PE composites," BioResources 16(4), 8049-8059. 8056 
which implies excellent strength and adhesion to reinforcement. In addition, hot melt polyurethane provides an advantage compared to polyesters due to its rapid processing, as they do not require drying time.

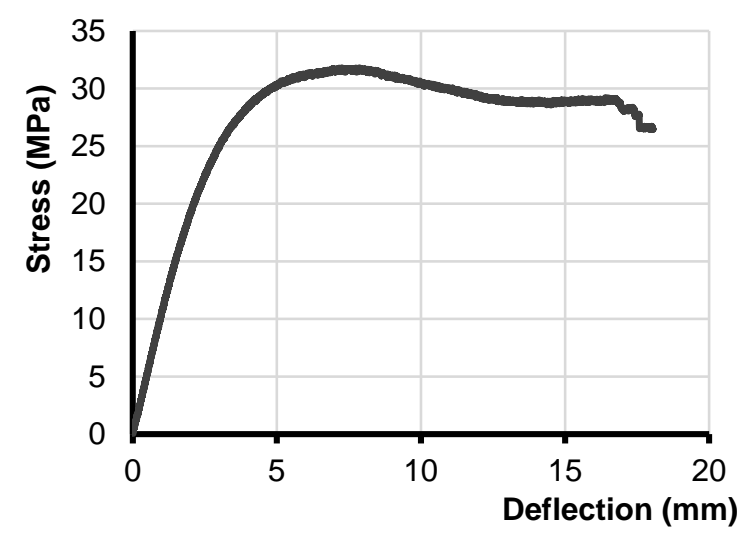

a. Polyurethane matrix

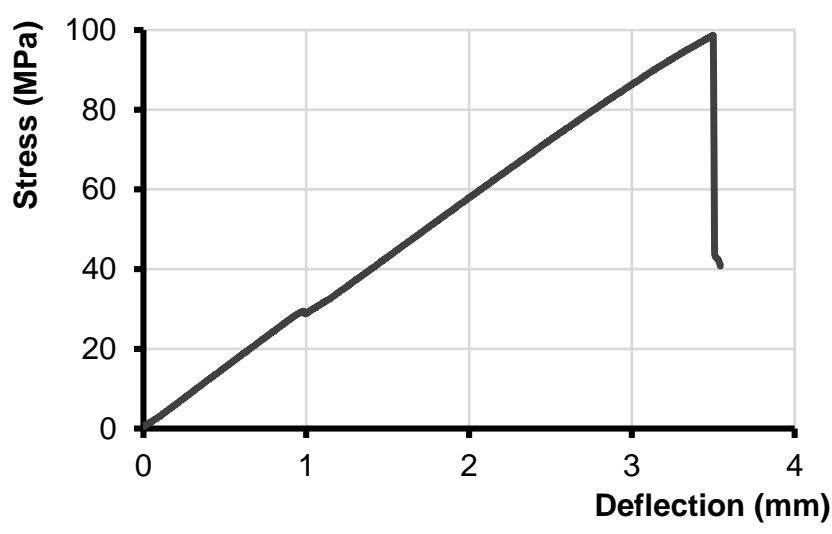

b. Polyester matrix

Fig. 5. Results of flexural tests on such composites

\section{CONCLUSIONS}

1. Guadua fiber is a good alternative as a reinforcement for making polymeric matrix composite materials. Guadua fiber can increase the strength by $266 \%$ of polyurethane matrix and $177 \%$ of polyester matrix. This means a considerable reduction in costs compared to the glass fibers or carbon fibers that are used today; they also have lower density and are friendly to the environment.

2. Tensile specimens made of polyester resin composite had a better performance than specimens with hot melt. This was attributed to high porosity, which reduces the mechanical properties. However, in the bending test the specimens of composite material with matrix of polyurethane did not fail and once the effort was removed, they began to recover the initial position. After a few minutes (5) they returned almost to their initial position.

\section{ACKNOWLEDGMENTS}

Authors want to express their gratitude to Universidad Tecnológica de Pereira for this funding and support.

\section{REFERENCES CITED}

Andrew, J. J., Srinivasan, S. M., Arockiarajan, A., and Dhakal, H. N. (2019). "Parameters influencing the impact response of fiber-reinforced polymer matrix composite materials: A critical review," Composite Structures 224, article no. 111007. DOI: 10.1016/j.compstruct.2019.111007 
Aruchamy, K., Pavayee Subramani, S., Palaniappan, S. K., Sethuraman, B., and Velu Kaliyannan, G. (2020). "Study on mechanical characteristics of woven cotton/bamboo hybrid reinforced composite laminates," Journal of Materials Research and Technology 9(1), 718-726. DOI: 10.1016/j.jmrt.2019.11.013

ASTM D3039 (2017). "Standard test method for tensile properties of polymer matrix composite materials," ASTM International, West Conshohocken, PA, USA. DOI: 10.1520/D3039_D3039M-17

ASTM D7264 (2015). "Standard test method for flexural properties of polymer matrix composite materials," ASTM International, West Conshohocken, PA, USA. DOI: 10.1520/D7264_D7264M-15

Barari, B., Ellingham T., Ghamhia I., Pillai K., El-Hajjar R., Lih-Sheng T. and Sabo, R. (2016). "Mechanical characterization of scalable cellulose nano-fiber based composites made using liquid composite molding process" Composites Part B, (84) 277-284. DOI:10.1016/j.compositesb.2015.08.040 1.

Borgaonkar, A. V., Mandale, M. B., and Potdar, S. B. (2018). "Effect of changes in fiber orientations on modal density of fiberglass composite plates," Materials Today: Proceedings 5(2), 5783-5791. DOI: 10.1016/j.matpr.2017.12.175

Canales, J., Muñoz, M. E., Fernández, M., and Santamaría, A. (2016). "Rheology, electrical conductivity and crystallinity of a polyurethane/graphene composite: Implications for its use as a hot-melt adhesive," Composites Part A: Applied Science and Manufacturing 84, 9-16. DOI: 10.1016/j.compositesa.2015.12.018

Chin, S. C., Tee, K. F., Tong, F. S., Ong, H. R., and Gimbun, J. (2020). “Thermal and mechanical properties of bamboo fiber reinforced composites," Materials Today Communications 23, article no. 100876. DOI: 10.1016/j.mtcomm.2019.100876

Guo, W., Kalali, E. N., Wang, X., Xing, W., Zhang, P., Song, L., and Hu, Y. (2019). "Processing bulk natural bamboo into a strong and flame-retardant composite material," Industrial Crops and Products 138, article no. 111478. DOI: 10.1016/j.indcrop.2019.111478

Kalali, E. N., Hu, Y., Wang, X., Song, L., and Xing, W. (2019). "Highly-aligned cellulose fibers reinforced epoxy composites derived from bulk natural bamboo," Industrial Crops and Products 129, 434-439. DOI: 10.1016/j.indcrop.2018.11.063

Kuehl, L. and Yiping, K., (2012). "Carbon off-setting with bamboo," INBAR Working Paper 71. International Network for Bamboo and RattandINBAR, Beijing, P.R. China.

Lokesh, P., Surya Kumari, T. S. A., Gopi, R., and Babu Loganathan, G. (2020). “A study on mechanical properties of bamboo fiber reinforced polymer composite," Materials Today: Proceedings 22, 897-903. DOI: 10.1016/j.matpr.2019.11.100

Lu, C., Hou, S., Zhang, Z., Chen, J., Li, Q., and Han, X. (2020). "The mystery of coconut overturns the crashworthiness design of composite materials," International Journal of Mechanical Sciences 168, article no. 105244. DOI: 10.1016/j.ijmecsci.2019.105244

Marulanda Arévalo, J. L., Martínez Casanova, M. A., Buendia, J. A., and Perez, A. P. (2019). "Characterization a polyurethane-based reactive hot melt adhesive for applications in materials," DYNA, 86(210), 247-253. DOI: 10.15446/dyna.v86n210.78244

Marulanda Arévalo, J. L., Reyes Gasga, J., Martínez Casanova, M. A., and Orozco Mendoza, E. A. (2020). "Composite material with polyurethane-based reactive hot-

Acosta et al. (2021). "Guada fiber PU PE composites," BioResources 16(4), 8049-8059. 8058 
melt matrix," Journal of Composite Materials. First Published August 17, 2020. DOI: 10.1177/0021998320950801

Sair, S., Mandili, B., Taqi, M., and el Bouari, A. (2019). "Development of a new ecofriendly composite material based on gypsum reinforced with a mixture of cork fibre and cardboard waste for building thermal insulation," Composites Communications, 16, 20-24. DOI: 10.1016/j.coco.2019.08.010

Sharma, A. K., Bhandari, R., Aherwar, A., and Rimašauskienè, R. (2020). "Matrix materials used in composites: A comprehensive study," Materials Today: Proceedings 21, 1559-1562. DOI: 10.1016/j.matpr.2019.11.086

Sormunen, P., and Kärki, T. (2019). "Recycled construction and demolition waste as a possible source of materials for composite manufacturing," Journal of Building Engineering 24, 100742. DOI: 10.1016/j.jobe.2019.100742

Tokala, V. N. B., and Mulpur, S. B. (2019). "Synthesis and mechanical behavior studies of bio-waste derived low-cost composite materials," Materials Today: Proceedings, 19, 2627-2632. DOI: 10.1016/j.matpr.2019.10.108

Trujillo, D. and López, L. (2016). "Bamboo material characterization," Nonconventional and Vernacular Construction Materials 365-390. DOI: 10.1016/B978-0-08-1000380.00013-5

Vaghasia, B., and Rachchh, N. (2018). "Evaluation of physical and mechanical properties of woven bamboo glass polyester hybrid composite material," Materials Today: Proceedings 5(2, Part 2), 7930-7936. DOI: 10.1016/j.matpr.2017.11.475

Article submitted: October 27, 2020; Peer review completed: December 19, 2020;

Revised version received and accepted: April 27, 2021; Published: October 15, 2021. DOI: 10.15376/biores.16.4.8049-8059 